\title{
The influence of process waters on optical properties during storage of hydrogen-peroxide bleached Norway spruce mechanical pulp
}

\author{
Sofia Enberg, Mats Rundlöf, Magnus Paulsson, Patrik Axelsson, Øyvind Eriksen and Per Engstrand
}

KEYWORDS: Chemical characterisation, Colour, Mechanical pulp, Metal ions, Optical properties, Process conditions, Process waters, Pulp storage, Spectral data

SUMMARY: To evaluate the causes behind the formation of colour in mill systems, the effect of different process waters on the optical properties of hydrogenperoxide bleached Norway spruce mechanical pulp during storage was studied. The influence of process water type, temperature, time, pulp consistency and $\mathrm{pH}$ was evaluated over the visible range of wavelengths. The darkening was more pronounced when pulp was stored in process waters compared to in distilled water. Increased temperature and prolonged storage times increased the darkening as expected, whereas a higher storage consistency gave less darkening than a lower storage consistency $(15 \%$ compared to $5 \%)$. The $\mathrm{pH}$ value that gave the lowest brightness reduction and a minimum in $\Delta k_{460}$ was found to be 5.5-6.0. Storage of pulp in white water from the paper machine resulted in a broad shoulder in the $k$ spectra indicating colour formation related to the particles in this water. Part of this shoulder in absorption spectra was related to added dyes, but the increase in absorption with time is likely to be caused by some other colour formation. The colour measured as $a^{*}$, $b^{*}$ showed that the storage changed the colour of the pulp towards red and yellow, and initially more towards red.

\section{ADRESSES OF THE AUTHORS:}

Sofia Enberg (sofia.enberg@norskeskog.com): Norske Skog Saugbrugs, NO-1756 Halden, Norway / FSCN, Mid Sweden University, SE-851 70 Sundsvall, Sweden

Mats Rundlöf (mats@capisco.se): Capisco Science \& Art, SE-602 34 Norrköping, Sweden / FSCN, Mid Sweden University, SE-851 70 Sundsvall, Sweden

Magnus Paulsson (magnus.paulsson@akzonobel.com): AkzoNobel Pulp and Performance Chemicals, SE-445 80 Bohus, Sweden / FSCN, Mid Sweden University, SE-851 70 Sundsvall, Sweden

Patrik Axelsson (patrik.axelsson@norskeskog.com): Norske Skog Saugbrugs, NO-1756 Halden, Norway Øyvind Eriksen (oyvind.eriksen@pfi.no): Paper and Fibre Research Institute, NO-7491 Trondheim, Norway Per Engstrand (Per.Engstrand@miun.se): FSCN, Mid Sweden University, SE-851 70 Sundsvall, Sweden Corresponding author: Sofia Enberg

The market for paper produced from mechanical pulp is declining steeply, especially for newsprint grades (Kallioranta, Ostle 2013) and, at the same time, the brightness (whiteness) demands for mechanical pulp based printing paper have risen ( Hill et al. 2010; Johnsen et al. 2010; Kuizhong et al. 2010). It is therefore important to be able to produce mechanical pulp with high brightness in a cost-efficient and environmentallyfriendly way. One drawback of mechanical pulp and mechanical pulp based paper is discolouration due to ultraviolet radiation and heat (see e.g. Forsskåhl 2000; Paulsson, Parkås 2012). Mill experience shows that the brightness of bleached mechanical pulp is often reduced along the process line from the bleach tower to the paper machine (Johnsen et al. 2010; Narvestad et al. 2011). This is a well-known and costly phenomenon (Narvestad et al. 2013a) and there may be several reasons for the discolouration, which most probably varies within one mill from time to time and from one mill to the next.

The brightness of unbleached and dithionite and/or hydrogen peroxide bleached softwood mechanical pulps has been reported to decrease during pulp storage (Gellerstedt et al. 1983; Harris, Karnis 1986; Lunan et al. 1986; Johnsen et al. 2010; Narvestad et al. 2011; Enberg et al. 2013; Narvestad et al. 2013a; Narvestad et al. 2013b; Narvestad et al. 2013c). In a previous study (Enberg et al. 2013) the effect of process conditions on the storage of chelated and well-washed, unbleached and hydrogen-peroxide bleached Norway spruce mechanical pulps was studied. Time and temperature $\left(50-80^{\circ} \mathrm{C}\right)$ were the process variables that had the largest impact on the discolouration whereas $\mathrm{pH}$ (4.3-9.7 at the beginning of storage) and pulp consistency (5-25\%) were of minor importance. The pulps bleached with hydrogen-peroxide were more sensitive to storage compared to the unbleached pulp at temperatures above $50^{\circ} \mathrm{C}$ (cf. Gellerstedt, Pettersson 1980). Harris and Karnis (1986) found that when latent unbleached thermomechanical pulp (TMP) was stored at $80^{\circ} \mathrm{C}$ and at high consistency (40\%), a loss in pulp strength due to residual fibre curl and a decrease in brightness due to an increase in the light absorption coefficient occur. The authors also reported that the light scattering coefficient was unchanged and that there was good correlation between the results obtained in mill trials and those obtained in controlled laboratory trials. Similar results were reported by Lunan et al. (1986) when storing unbleached TMP at high consistency $(50 \%)$ at temperatures exceeding $65^{\circ} \mathrm{C}$, i.e. that the aged pulp developed a residual latency due to curl-setting and that this was not removable by longer periods of disintegration. Further, a strong correlation between the storage temperature and the brightness loss was observed; storage at $50^{\circ} \mathrm{C}$ did not lower the brightness, while temperatures exceeding $80^{\circ} \mathrm{C}$ strongly discoloured the pulp. The changes in the light scattering coefficient were minor for all aging temperatures in the interval $50-100^{\circ} \mathrm{C}$ (Lunan et al. 1986). Storing hydrogenperoxide bleached TMP at low consistency ( 4\%) was reported to result in brightness losses already at $55^{\circ} \mathrm{C}$ (Johnsen et al. 2010; Narvestad et al. 2011) and 
increasing the temperature to $65^{\circ} \mathrm{C}$ aggravated the discolouration (Narvestad et al. 2011). The extent of reversion was due to $\mathrm{pH}$ and the type of dilution water; the brightness stability was highest when $\mathrm{pH}$ was 5.0-5.5 (cf. Gellerstedt et al. 1983) and when the pulp was diluted with clear filtrate instead of unfiltered process water. Furthermore, there was good correlation between the results obtained in laboratory trials and the results obtained at the mill (Johnsen et al. 2010; Narvestad et al. 2011).

In addition to discolouration caused by elevated temperatures, components in the dilution water may affect the discolouration either directly, upon contact with the pulp, or by accelerating the heat-induced reactions. Transition metal ions are known to accelerate the heat and alkali-induced darkening (Gupta 1970; Ni et al 1997) of mechanical pulp, and iron in both ferrous and ferric form affect the colour and discolouration when storing high yield pulps (Gupta 1970; Gellerstedt, Pettersson 1980; Gellerstedt et al. 1983; Johnsen et al. 2010; Narvestad et al. 2013a; Narvestad et al. 2013b). Metal ions in a concentration typical for tap water (Fe: $\sim 0.3 \mathrm{mg} / \mathrm{l} ; \mathrm{Cu}: \sim 0.04 \mathrm{mg} / \mathrm{l})$ are sufficient to reduce the pulp brightness by up to four units and accelerate the heat-induced yellowing of various types of high-yield pulps (Ni et al. 1997). Hydrogen-peroxide bleached pulps were found to be more sensitive compared to unbleached pulps, probably due to the formation of new functional groups (e.g. phenolic hydroxyl groups) during bleaching that could participate in auto-oxidation reactions or form coloured metal ion complexes. Others have reported that reductively (dithionite) bleached pulps are more sensitive to metal ions in process waters compared to oxidatively bleached (hydrogen peroxide) pulps, and this was ascribed to a more extensive formation of coloured metallic complexes with lignin structures in the dithionite-bleached pulps (Mao, Ni 2008). Furthermore, Johnsen et al. (2010) reported a brightness reduction when mechanical pulp was stored together with a nonspecified paper additive containing significant amounts of metals. Narvestad et al. (2013a) reported that filler clay may induce discolouration by up to seven units of brightness in a Norway spruce mechanical pulp. The clay-induced brightness reduction was attributed to the dissolution of iron from the clay. Furthermore, other metals (e.g. copper) and organic components (e.g. dissolved lignin and extractives) in process waters as well as residual bleaching and paper chemicals may influence heat-induced discolouration during pulp storage (Johnsen et al. 2010; Gellerstedt, Pettersson 1980; Ni et al. 1997; Rundlöf et al. 2000a; Rundlöf et al. 2000b). The darkening of precipitated calcium carbonate and precipitated calcium sulfate in the wet end of a paper machine was attributed to the adsorption of wood based dissolved and colloidal substances from the water phase onto the surface of the fillers (Varhimo et al. 2012) Residual hydrogen peroxide in process water may, however, improve the brightness of unbleached pulp during storage (Ferritius, Lundström 2011).

There are different opinions regarding the mechanisms for heat-induced discolouration of high-yield pulp. One is that the mechanism for heat-induced darkening is caused by the formation of chromophores in lignin (Gellerstedt, Pettersson 1980; Gellerstedt et al. 1983; Gratzl 1985; Chong et al. 1991). Another opinion is that the mechanism also involves carbohydrates (Luo et al. 1988; Holmbom et al. 1992; Grossmann, Ott 1994; Beyer et al. 1995; Forsskåhl et al. 2000). Gellerstedt and Pettersson (1980) showed that hydroquinone and catechol structures in lignin may give rise to rapid discolouration of ligninrich pulps when exposed to oxygen due to the formation of para- and ortho-quinones as the primary reaction products and that the auto-oxidation was accelerated in the presence of heavy metal ions. It has been shown that phenoxyl radicals are formed during heat-induced aging of mechanical pulp and that these radicals are transformed into quinones (Gellerstedt et al. 1983). Transition metal ions, especially ferrous and ferric ions, form strongly coloured complexes with lignin and extractives (Gore, Newman 1964; Gupta 1970; Polcin, Rapson 1972; Meshitsuka, Nakano 1973; Hon, Glasser 1979; Moldenius 1983; Zhang, Gellerstedt 1994; Gosh, Ni 1998; Ni el al. 1999; Yoon et al. 1999; Forsskåhl 2000; Peart, Ni 2001; Friman et al. 2004) and may therefore contribute to the colour and discolouration of mechanical pulp as well as lignin and extractive model compounds. In general, the absorption bands of these complexes are broad, often covering the whole visible spectrum (Polcin, Rapson 1972; Moldenius 1983; Ghosh, Ni 1998; Ni et al. 1999; Peart, Ni 2001; Friman et al. 2004).

The purpose of this work is to evaluate the effect of different process waters on the optical properties of a hydrogen-peroxide bleached Norway spruce mechanical pulp during storage; this was done to obtain a more detailed description of the causes behind the formation of colour in mill systems. The influence of process water type, temperature, time, pulp consistency and $\mathrm{pH}$ was evaluated over the visible range of wavelengths.

\section{Material and Methods}

\section{Materials}

\section{Pulp}

Mechanical pulp made from Norway spruce (Picea abies) was taken from a mill producing super calendered (SC) paper. The hydrogen-peroxide bleached pulp was collected from the wash press after a high consistency bleach tower. The pulp consisted of $93 \%$ thermomechanical pulp and 7\% groundwood pulp. Magnesium hydroxide was used as the alkali source during hydrogen-peroxide bleaching. The pulp was washed in two stages before further treatment in order to reduce the metal content and amount of dissolved organic material. The first washing stage $(\mathrm{Q})$ was performed with $2.0 \mathrm{~kg} / \mathrm{bdt}$ diethylenetriaminepentaacetic acid, pentasodium salt (Dissolvine D-40-K from AkzoNobel Functional Chemicals, Amersfoort, the Netherlands) at $4 \%$ pulp consistency (p.c.) at $50^{\circ} \mathrm{C}$ for $30 \mathrm{~min}$. The second stage $(\mathrm{W})$ was performed with distilled water at $3 \%$ p.c. at $20^{\circ} \mathrm{C}$ for $30 \mathrm{~min}$. After each washing stage, the pulp was dewatered on a wire cloth (Monodur PA 112, 
from Derma, Gråbo, Sweden) and the filtrate recirculated once to avoid loss of fibre and fines. The pulp was then centrifuged to a dry content of about $35 \%$ and stored in a freezer at $-24^{\circ} \mathrm{C}$ until further use. For comparison, some experiments were also performed on the unwashed pulp. Distilled water was used in all pulp washing and laboratory trials described below unless otherwise stated.

\section{Process waters}

Process waters were taken from different positions in the production line at a mill producing SC paper. The process waters were chosen to represent a variety in composition and character. The process waters were: white water from the paper machine (WW PM), clear filtrate from the paper machine (CF PM), bleach filtrate from the wash press after hydrogen-peroxide bleaching (Bleached filtrate) and clear filtrate from TMP (CF TMP). The residual hydrogen peroxide in Bleached filtrate and $\mathrm{CF}$ TMP was decomposed by addition of the enzyme catalase. Any possible effects from having residual hydrogen peroxide present during storage were therefore not studied here. The process waters were used in the storage trials both as received and after centrifugation (1500 $\mathrm{G}(3040 \mathrm{rpm})$ for $10 \mathrm{~min})$ to obtain the dissolved and colloidal phase with a very low content of solid particles such as fines or fillers. Some of the waters were collected on two different occasions (named A and B).

\section{Methods}

\section{Metal, sulfur and nitrogen analyses}

The metal and sulfur contents of pulp and process waters were analysed after wet combustion with nitric acid $(65 \%$ concentration, trace analysis, from Fluka Analytical) using a microwave system with an inductively coupled plasma (ICP) instrument (IRIS Advantage s/n 10973). The report limits in pulp ( $\mathrm{mg} / \mathrm{kg}$ ) for $\mathrm{Ca}, \mathrm{Cu}, \mathrm{Fe}, \mathrm{K}, \mathrm{Mg}$, $\mathrm{Mn}$ and $\mathrm{Na}$ were 20,0.1, 0.5, 10, 20, 0.1 and 5 respectively. The report limits in process water $(\mathrm{mg} / \mathrm{l})$ for $\mathrm{Al}, \mathrm{Ca}, \mathrm{Cu}, \mathrm{Fe}, \mathrm{Mg}, \mathrm{Mn}, \mathrm{Na}, \mathrm{S}$ and $\mathrm{Si}$ were $0.04,0.2$, $0.02,0.04,0.1,0.02,2,1.3$ and 0.2 respectively. The nitrogen content in process waters was analysed according to the standard method SS 28101, Nitrogen content of water - Determination with Kjeldahl method after reduction with Devarda's alloy. The report limit was $7 \mathrm{mg} / \mathrm{l}$.

\section{Standard analyses of process waters}

The process waters were analysed according to the following standard methods: Chemical oxygen demand (COD), ISO 15705:2002; suspended solids (SS), ISO 11923:1997/NS 4733:1983; conductivity, ISO 7888:1985 and turbidity, ISO 7027:1999. The ash content was determined by combustion of the SS filter in an oxygen atmosphere.

\section{Chemical analyses of process waters}

Gravimetrical determination of the content of extractives was carried out by extracting the samples three times with methyl tert-butyl ether (MTBE, from Romil Ltd.) with a $\mathrm{pH}$ of 3.5 . The combined extracts were then evaporated, dried at $105^{\circ} \mathrm{C}$ and weighed. The sample volume was $50 \mathrm{ml}$ and $3 \times 40 \mathrm{ml}$ MTBE was used.

The composition of extractives (lignans and lipophilic extractives such as fatty acids, resin acids, sterols, steryl esters and triglycerides) was determined according to the method described by Örså and Holmbom (1994) with the following exceptions: the process waters were analysed as received, i.e. no filtration or centrifugation was applied, but the sample bottles were carefully shaken before samples were taken out. The combined extracts were evaporated using nitrogen steam and the sample was dried with $\mathrm{Na}_{2} \mathrm{SO}_{4}$ (from Acros Organics) before silylation. $100 \mu \mathrm{l}$ bis-(trimethylsilyl)-trifluoro-acetamide (from Fluka Analytica) and $50 \mu \mathrm{l}$ trimethylchlorosilane (from Aldrich Chemistry) was added to the residue and the solution was heated at $70^{\circ} \mathrm{C}$ for $30 \mathrm{~min}$. After silylation, the sample was cooled down before being transferred to a gas chromatography (GC) injection glass. The GC instrument used was an Agilent Technologies 7890 equipped with a flame ionisation detector and an Agilent Technologies DB-1 column (length 7.5; inner diameter, $0.53 \mathrm{~mm}$; film thickness, $0.15 \mu \mathrm{m})$. The temperature profile used was $90^{\circ} \mathrm{C}$ for $1.5 \mathrm{~min}$, then a temperature increase of $12^{\circ} \mathrm{C} / \mathrm{min}$ to $340^{\circ} \mathrm{C}$ which was maintained for 5 minutes. The detector temperature was $340^{\circ} \mathrm{C}$. The system uses helium as a carrier gas.

The water sample after MTBE extraction was analysed for the amount of lignin-like substances by ultraviolet (UV) spectroscopy at $280 \mathrm{~nm}$ (extinction coefficient, $19 \mathrm{l} / \mathrm{mg}, \mathrm{cm}$ ). Before analysis, the $\mathrm{pH}$ of the sample was adjusted back to the starting value of the process water with sodium hydroxide (from Merck, pro analysi). The UV absorbance was measured with a UV-1800 Shimadzu instrument.

\section{pH adjustment}

In some of the trials, $\mathrm{pH}$ was varied to evaluate the effect of $\mathrm{pH}$ during storage. The dose of hydrochloric acid or sodium hydroxide (both from Merck, pro analysi) giving $\mathrm{pH} \sim 4-8$ after storage was optimised for each type of process water. The washed pulp was mixed with process water or distilled water and stored for five minutes at room temperature prior to $\mathrm{pH}$ adjustment. Hydrochloric acid or sodium hydroxide was then added to the pulp suspension. The $\mathrm{pH}$ after five minutes was recorded as the "starting $\mathrm{pH}$ ".

\section{Storage trials}

The pulp storage trials were performed at controlled temperatures in a water bath. For trials without $\mathrm{pH}$ adjustment, the pulp was mixed with water and stored for five minutes at room temperature before $\mathrm{pH}$ was measured. After measuring the starting $\mathrm{pH}$, the pulp suspension was transferred to a polyethylene bag, and the bag was then sealed and placed in a water bath to simulate pulp tower storage. After the storage time had elapsed, the bag was placed in cold water for the pulp to cool down before measuring $\mathrm{pH}$ and proceeding to sheet formation. For the storage time 0 hours, sheet formation started directly after measuring $\mathrm{pH}$. 
Table 1 - Some characteristics of the process waters used. Values in parentheses represent values for the waters after centrifugation. Some waters were taken out on two different occasions named $A$ and $B$.

\begin{tabular}{lcccccc}
\hline & $\begin{array}{c}\text { Suspended solids } \\
(\mathbf{m g} / \mathbf{l})\end{array}$ & $\begin{array}{c}\text { Ash content } \\
\text { (mg/l) }\end{array}$ & $\begin{array}{c}\text { Turbidity } \\
\text { (NTU) }\end{array}$ & $\begin{array}{c}\text { COD } \\
(\mathbf{m g} / \mathbf{l})\end{array}$ & pH & $\begin{array}{c}\text { Conductivity } \\
(\mathbf{m S} / \mathbf{c m})\end{array}$ \\
\hline CF TMP & $260(170)$ & $0(0)$ & $390(370)$ & $2200($ n.a.1) & $5.3($ n.a.1) & $0.8($ n.a.1) \\
Bleached filtrate & $600(110)$ & $32(13)$ & $400(280)$ & $3100(2920)$ & $7.5(7.6)$ & $2.2(0.8)$ \\
CF PM A & $62(35)$ & $0(0)$ & $60(56)$ & $280(293)$ & $6.2($ n.a.1) & $0.6($ n.a.1) \\
CF PM B & 13 & 6 & 19 & 560 & 5.5 & 1.1 \\
WW PM A & $9600(12)$ & $7700(0)$ & $11000(34)$ & $240(230)$ & $6.1($ n.a.1) & $0.5($ n.a.1) \\
WW PM B & 8900 & 6100 & n.a.1 & 640 & 5.4 & 1.1 \\
\hline
\end{tabular}

${ }^{1}$ not analysed

Distilled water and the four process waters, both as received and after centrifugation, were stored together with the washed pulp for five hours at $5 \%$ pulp consistency at $50^{\circ} \mathrm{C}$ or $65^{\circ} \mathrm{C}$. The pulp was also stored at a higher concentration, $15 \%$, at $65^{\circ} \mathrm{C}$ for $5 \mathrm{~h}$. To each consistency a constant volume of water was added to a certain amount of pulp, and any possible solid material in the waters was not taken into account. Furthermore, the mechanical pulp was stored for longer periods of time in Bleached filtrate, CF PM, WW PM and distilled water at $65^{\circ} \mathrm{C}$ and 5\% pulp consistency: 5, 12 (not for Bleached filtrate), 24, 48, and 72 hours. Storage trials were performed in CF PM, WW PM and distilled water at varying $\mathrm{pH}$-levels, $\sim 4-8$ (measured after storage), at $65^{\circ} \mathrm{C}$ and $5 \%$ pulp consistency for 5 hours. In every experiment, sheets were made of the pulp and water mixture before storage ( 0 hours) and used as a reference. The WW PM and CF PM named A were used in the first trials, corresponding waters named B were used in the trials with longer storage times and in the trials where the $\mathrm{pH}$ was varied.

\section{Sheet formation}

Laboratory sheets with a grammage of approximately 64 $\mathrm{g} \mathrm{m}^{-2}$ (conditioned at $23^{\circ} \mathrm{C}$ and $50 \%$ relative humidity according to ISO standard method 187:1990) were produced on a small sheet former according to the method described by Karlsson et al. (2012). The sheet former had a 200 mesh wire with a diameter of $112 \mathrm{~mm}$. To increase the retention of material, a retention chemical was added during disintegration. The retention chemical was a polyamine received from AkzoNobel Pulp and Performance Chemicals (Eka ATC 4150), and the charge was $1.5 \mathrm{~kg} / \mathrm{bdt}$. Pulp sufficient for two laboratory sheets was disintegrated at $1 \%$ pulp consistency at $85^{\circ} \mathrm{C}$ for one minute using a Braun $300 \mathrm{~W}$ hand mixer with blunt mixing blades. The pulp suspension was then diluted with cold water to $0.2 \%$ p.c., the retention chemical was added, and the suspension was then disintegrated for one additional minute. A sodium acetate buffer (prepared with $136.08 \mathrm{~g} \mathrm{CH}_{3} \mathrm{COONa} \times 3 \mathrm{H}_{2} \mathrm{O}, 31.8 \mathrm{ml}$ concentrated $\mathrm{CH}_{3} \mathrm{COOH}$ and distilled water to one litre) was used to adjust the $\mathrm{pH}$ of the pulp suspension to $\mathrm{pH} 5.0$ prior to sheet formation. The laboratory sheets were then pressed $(5+2 \min , 410 \mathrm{kPa}$ over the area of the sheet), dried and conditioned at $23^{\circ} \mathrm{C}$ with $50 \%$ relative humidity as described in standards ISO 5269-1:1998 and ISO 187:1990 respectively. Sheets with a grammage of approximately $210 \mathrm{~g} / \mathrm{m}^{2}$ were made to obtain an opaque background when measuring the optical properties. In this case, the pulp was disintegrated in cold water $\left(20^{\circ} \mathrm{C}\right)$ at $3 \%$ p.c. for $30 \mathrm{sec}$. A sodium acetate buffer (same recipe as above) was added to the pulp suspension, and the sheets were dewatered on a Büchner funnel. The sheets were then pressed for two minutes at $410 \mathrm{kPa}$ and dried and conditioned at $23^{\circ} \mathrm{C}$ with $50 \%$ relative humidity.

\section{Optical measurements}

The measurement of optical properties was made on the top side of the laboratory sheets using a Lorentzen \& Wettre Elrepho SE 070 instrument. ISO brightness, CIE $L^{*}, a^{*}, b^{*}$ co-ordinates, light scattering $(s)$ and light absorption $(k)$ coefficients were determined according to standard procedures ISO 2470:1999, ISO 5631:2000 and ISO 9416:1998 respectively.

\section{Results and Discussion}

\section{Characteristics of process waters}

The hydrogen-peroxide bleached Norway spruce mechanical pulp was stored together with various types of process waters taken from four positions along the process line:

- Clear filtrate from the TMP mill before bleaching, "CF TMP".

- Filtrate from the press after the bleach tower, "Bleached filtrate".

- Clear filtrate from the paper machine, "CF PM".

- White water from the paper machine, same as above but not filtered, "WW PM".

Table 1 shows some characteristics of the analysed process waters.

Two samples from the pulp mill, CF TMP and Bleached filtrate, contained some suspended solids which could partly be removed by centrifugation. The CF TMP contained only organic solids and the major part of the solids in the Bleached filtrate were organic, but a small ash content could be measured. This inorganic material may at least partly originate from the suspended 
Table 2 - The content of some metals, sulfur and nitrogen in the process waters examined. Values in parentheses represent values for the water after centrifugation. Some waters were taken out on two different occasions named $A$ and $B$.

\begin{tabular}{lcccccccccc}
\hline Me $(\mathbf{m g} / \mathbf{l})$ & $\mathbf{A l}$ & $\mathbf{S i}$ & $\mathbf{F e}$ & $\mathbf{M g}$ & $\mathbf{C a}$ & $\mathbf{N a}$ & $\mathbf{M n}$ & $\mathbf{C u}$ & $\mathbf{S}$ & $\mathbf{N}$ \\
\hline CF TMP & 1.2 & 5.3 & 0.74 & 81 & 42 & n.a. ${ }^{1}$ & 11 & 0.08 & 67 & 19 \\
Bleached filtrate & 0.67 & 6.1 & 1.0 & 230 & 31 & 160 & 2.4 & 0.04 & 110 & 17 \\
CF PM A & 4.8 & 7.2 & 0.44 & 33 & 5.8 & n.a. ${ }^{1}$ & 0.06 & 0.03 & n.a. ${ }^{1}$ & n.a. ${ }^{1}$ \\
CF PM B & 0.27 & 4.8 & 0.39 & 57 & 9.3 & 130 & 0.28 & $<0.02$ & 160 & $<7$ \\
WW PM A & 0.29 & 1.6 & 0.16 & 28 & 5.1 & 55 & 0.05 & 0.02 & 66 & n.a. ${ }^{1}$ \\
& $(0.74)$ & $(1.0)$ & $(0.24)$ & $(22)$ & $(4.4)$ & $(\text { n.a. })^{1}$ & $(0.05)$ & $(0.02)$ & $(53)$ & \\
WW PM B & 0.46 & 5.3 & 1.9 & 53 & 8.9 & 120 & 0.28 & $<0.02$ & 140 & $<7$ \\
\hline
\end{tabular}

${ }^{1}$ not analysed

$\mathrm{Mg}(\mathrm{OH})_{2}$ used as an alkali source in the bleach plant, also indicated by the high $\mathrm{Mg}$ content in the water phase (see Table 2) and possibly the higher $\mathrm{pH}$. The COD values were the highest by far, indicating that the major part of the contents of these two samples were organic. The COD values remained about the same before and after centrifugation, which was the case for all samples, indicating that the COD was caused by dissolved and/or colloidal substances. The COD values of the clear filtrate, CF PM, were on the same level as those of the unfiltered white water, WW PM.

The unfiltered white water from the paper machine, WW PM, contained the highest amounts of suspended solids, and also had the highest turbidity. These suspended solids were inorganic, most probably filler clay, and could be removed almost completely by centrifugation (represented by values in parentheses in Table 1). The corresponding clear filtrate, CF PM, contained the smallest amounts of suspended solids, with an ash content close to zero.

Both WW PM and CF PM were taken out on two different occasions (18 months difference), on the first occasion the production was a standard quality of paper whereas on the second occasion it was a high-bright quality produced with an increased charge of bleaching chemicals. There were some differences: the COD and conductivity were lower for both waters at the first sampling; $\mathrm{pH}$ and turbidity were higher.

In Table 2, the contents of some metals, sulfur and nitrogen for the different process waters are shown. These measurements were made on the clear water phase of the samples, which means that the contribution from any solids was small. In general, the metal content was judged to be within the normal range for this type of process. The higher concentrations of magnesium in the samples from the pulp mill were most probably due to the
$\mathrm{Mg}(\mathrm{OH})_{2}$ used as an alkali source in the bleaching. The content of metals known to cause darkening (Gupta 1970; $\mathrm{Ni}$ et al. 1997), iron and copper, was low in all waters. The iron content of WW PM was $0.16 \mathrm{mg} / \mathrm{l}$ in the first sample "A" and more than ten times higher, $1.9 \mathrm{mg} / \mathrm{l}$, in the second sample " $\mathrm{B}$ ". This is still, however, considered to be a low iron content. When as much as possible of the solid material in the WW PM was dissolved in acid, the iron content was much higher: $19 \mathrm{mg} / \mathrm{l}$ for WW PM A and $20 \mathrm{mg} / \mathrm{l}$ for WW PM B. This shows that the suspended solids contain metals which may affect the pulp if they can be dissolved into the water phase. Nitrogen was measured to indicate if DTPA (diethylenetriaminepentaacetic acid) was present in the sample. The addition of DTPA in the TMP plant is placed before the sample point of both CF TMP and Bleached filtrate. The content of nitrogen was higher for the TMP waters compared to the PM waters, which may indicate that some DTPA is present in these waters. The sulfur content mainly originates from the addition of bisulfite as acidification after hydrogen peroxide bleaching and possibly also from post-bleaching with sodium dithionite on the paper machine. The higher sulfur content in the WW PM B waters can be explained by the higher dose of chemicals used when the high-bright quality was produced.

Table 3 shows contents of extractives and lignin. The content of extractives was much higher in the waters from the TMP plant, Bleached filtrate and CF TMP compared with CF PM and WW PM waters from the paper mill. This corresponds with the high COD and turbidity values (Table 1), which was expected as lipophilic extractives are present in the form of colloidal particles also after hydrogen-peroxide bleaching (Thornton et al. 1991). The composition of extractives was considered to be within the normal range for this

Table 3 - The content of lignin and extractives in the process waters.

\begin{tabular}{|c|c|c|c|c|c|c|c|c|c|c|}
\hline \multirow{3}{*}{$\begin{array}{l}\text { Process } \\
\text { water }\end{array}$} & \multirow{3}{*}{$\begin{array}{c}\text { Lignin } \\
(\mathrm{mg} / \mathrm{l})\end{array}$} & \multirow{3}{*}{$\begin{array}{c}\text { Gravimetric } \\
\text { extractives } \\
\text { (mg/l) }\end{array}$} & \multicolumn{6}{|c|}{ Extractives from GC analyse } & \multirow[b]{3}{*}{$\begin{array}{l}\text { SUM } \\
(\mathrm{mg} / \mathrm{l})\end{array}$} & \multirow[b]{3}{*}{$\begin{array}{l}\% \text { found } \\
\text { from } \\
\text { gravimetric }\end{array}$} \\
\hline & & & \multicolumn{6}{|c|}{ Part of sum (\%) } & & \\
\hline & & & Lignans & $\begin{array}{l}\text { Steryl } \\
\text { esters }\end{array}$ & Sterols & $\begin{array}{l}\text { Tri- } \\
\text { glyce- } \\
\text { rides }\end{array}$ & $\begin{array}{l}\text { Fatty } \\
\text { acids }\end{array}$ & $\begin{array}{l}\text { Resin } \\
\text { acids }\end{array}$ & & \\
\hline CF TMP & 328 & 478 & 69.6 & 7.6 & 6.8 & 7.2 & 4.5 & 4.3 & 246 & 51 \\
\hline $\begin{array}{l}\text { Bleached } \\
\text { filtrate }\end{array}$ & 258 & 320 & 49.4 & 13.0 & 6.8 & 14.8 & 4.5 & 11.6 & 126 & 39 \\
\hline CF PM B & 80 & 63 & 70.0 & 5.7 & 9.5 & 0.4 & 7.4 & 7.4 & 28.3 & 45 \\
\hline WW PM B & 68 & 90 & 33.5 & 14 & 6.6 & 28.2 & 9.8 & 7.9 & 52.8 & 58 \\
\hline
\end{tabular}


process and wood species (Ekman et al. 1990). The lignin content was also much higher in the TMP waters. In the GC analyses of extractives, only up to $\sim 60 \%$ of the extractives found in the gravimetric determination could be detected. Thus, there are some extractives that are not included in the GC determination, for example phenolic compounds such as stilbenes and tannins that may contribute to colour as such or in combination with metals (Polcin et al. 1969; Ni el al. 1999; Friman et al. 2004).

\section{The influence of process waters on pulp brightness and light absorption coefficients}

The pulp used in all experiments with only a few exceptions was washed in a two stage procedure. After the two-stage laboratory washing procedure, the concentration of all measured metals was very low, and the wash did not affect the optical properties of the pulp. The iron content was $17 \mathrm{mg} / \mathrm{kg}$ before the wash and $11 \mathrm{mg} / \mathrm{kg}$ after the wash. The manganese content was $2.8 \mathrm{mg} / \mathrm{kg}$ before the wash and $0.2 \mathrm{mg} / \mathrm{kg}$ after the wash. The copper content was $<0.1 \mathrm{mg} / \mathrm{kg}$ both before and after wash. The brightness was $73.9 \%$ ISO before the wash and $74.1 \%$ ISO after the wash. Detailed characteristics before and after the washing procedure can be found in Enberg et al. (2013).

Fig 1 deals with the changes in brightness and $k_{460}$ evaluated in two different ways: $i$ ) the difference between dilution with distilled water and process waters before storage (Fig $1 a$ and $b$ ); ii) the effect of storage in different waters over time, i.e. a comparison of optical properties directly after dilution with those after $5 \mathrm{~h}$ of storage (Fig $1 c$ and $d$ ). When the clear filtrate from the pulp mill, CF TMP, was mixed with the washed pulp, the brightness and $k$-values were unaffected; the brightness was $75.0 \%$ ISO for CF TMP compared to $74.8 \%$ ISO for the clean system. For the Bleached filtrate, the brightness decreased to $74.1 \%$ ISO and the $k_{460}$-value increased, this means that the darkening of the pulp was caused by the formation of coloured groups. After centrifugation, the increase in $k$ became higher and the $s$-value increased (Fig 1b), which caused a smaller brightness loss compared to using the water as received. The Bleached filtrate contained some suspended solids, of which only a small part was inorganic. The increase in $s$ is probably related to the removal of these particles. It is possible that small particles may fill pores in the sheet that would otherwise scatter light. The increase in $s$ of the centrifuged bleached filtrate is also accompanied by a decrease in the sheet density as compared to the water as received. Therefore it may be speculated that the suspended solids could have contributed to the strength of the sheet and thereby a lower $s$ compared with the centrifuged water.

Using CF PM for dilution, the brightness increased to $75.4 \%$ ISO whereas the $k_{460}$ remained more or less unchanged. The increase in brightness was attributed to a higher light scattering. The higher light scattering of the CF PM was not caused by filler material present in this water since the ash content was zero (cf. Table 1). It may be related to a lower density and strength, giving a more porous sheet structure. For WW PM, both the brightness (76.1\% ISO) and the $k_{460}$ increased. The increase in brightness was most probably due to the light scattering of the filler material present in the WW PM. The $s$-values at $460 \mathrm{~nm}$, before and after centrifugation, are included in Fig 1 b. For the pulp in distilled water, the light scattering coefficient at $460 \mathrm{~nm}$ was $71.5 \mathrm{~m}^{2} / \mathrm{kg}$, and when WW PM was added the $s$-value became $92.7 \mathrm{~m}^{2} / \mathrm{kg}$. The removal of solid particles by centrifugation naturally gave a lower contribution to the $s$-value and therefore a lower brightness. Nevertheless, the centrifuged WW PM increased the $s$-value as compared to the case with distilled water in a similar way to the CF PM (as may be expected).

The light scattering coefficient for pulps stored at $15 \%$ pulp consistency are not included in Fig $1 b$ as the value is influenced by the amount of material added, and a higher consistency means less material. For WW PM, the light scattering coefficient at $15 \%$ pulp consistency was $79.8 \mathrm{~m}^{2} / \mathrm{kg}$ as compared to $92.7 \mathrm{~m}^{2} / \mathrm{kg}$ at $5 \%$. There were some experimental variations in the light scattering coefficients, though the light scattering coefficients did not change in a systematic way as a consequence of storage.

These results shows the importance of using $s$ - and $k$ values to interpret changes in the measured reflectance factors such as brightness, as the light scattering coefficient varies along the process line. If the fibres darken due to formation of colour and $s$ increases at the same time, the net effect on brightness may be zero or positive, and the formation of colour may therefore pass unnoticed.

The discolouration, measured as an increase in $k_{460}$, was more pronounced when the pulp was stored in process waters compared to when it was stored in distilled water for all storing conditions studied (Fig 1 d). At $50^{\circ} \mathrm{C}$, the discolouration was small or negligible. An increase in temperature to $65^{\circ} \mathrm{C}$ increased the discolouration, as expected. When the pulp was stored at a higher consistency, $15 \%$ compared to $5 \%$, the increase in $k_{460}$ was less for all waters, probably because a higher pulp consistency means less dilution with process water and the amounts of material causing discolouration decreases. In a previous study (Enberg et al. 2013), when pulp was stored in a clean system, the pulp consistency in the interval 5-25\% was of minor importance. However when process waters are used for dilution, a higher consistency during storage seems to be preferable to preserve a high brightness. This result seems to contradict the results of Harris and Karnis (1986) and Lunan et al. (1986). In both these studies, unbleached refiner pulp was diluted with water to various consistencies, resulting in a larger decrease in brightness when the pulp was stored at a higher consistency compared to a lower consistency (however, in the study by Lunan et al. (1986) the brightness loss was unaffected by pulp consistency in the range 14-50\%). Pulp taken out after refining is not as clean as the bleached and washed pulp used in the present study. When the refiner pulp is diluted with water, a higher pulp consistency means less water, which could explain the different results achieved. 

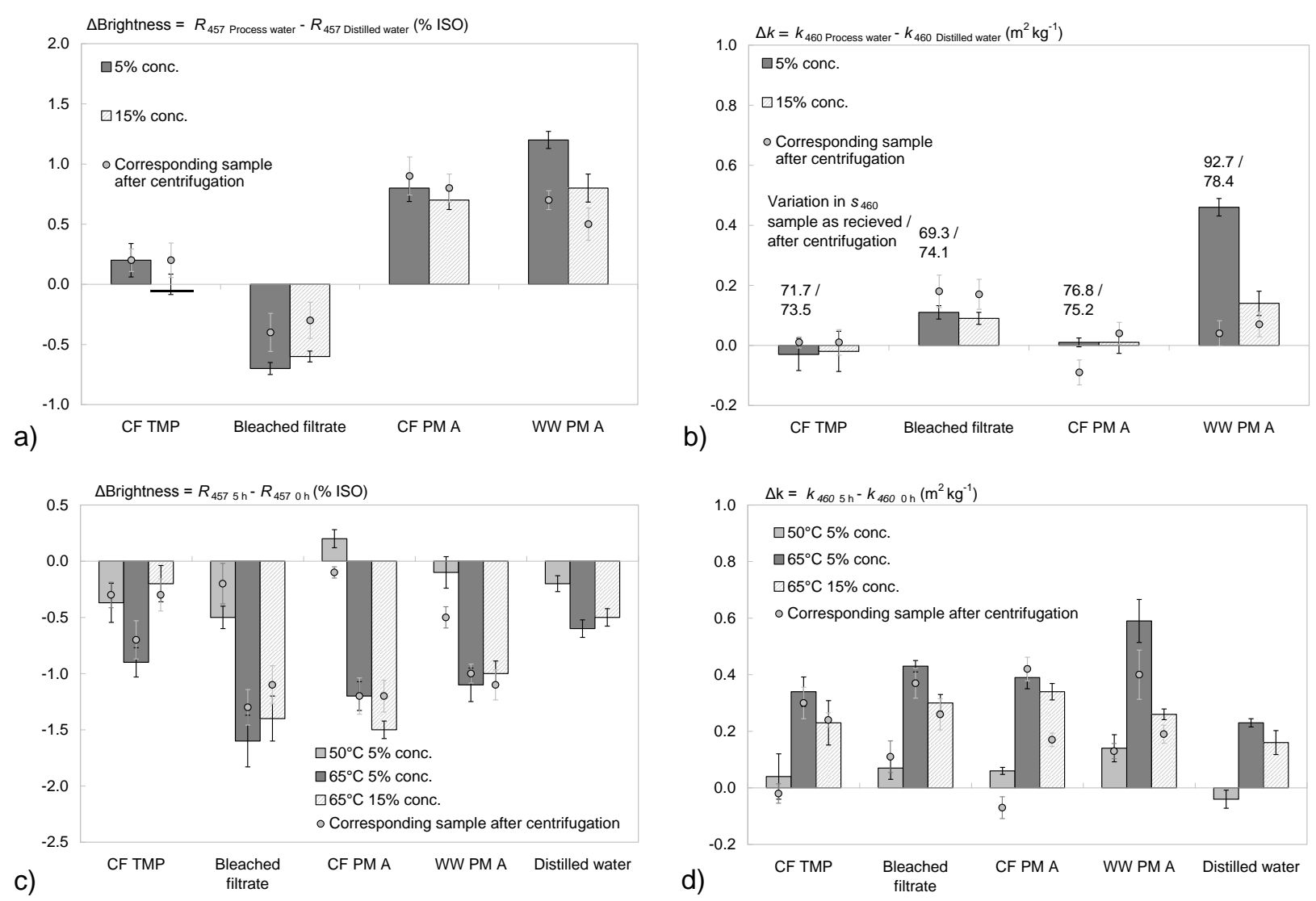

Fig 1 a-d - Change in ISO brightness and $k_{460}$ upon dilution and/or storage of a well-washed hydrogen-peroxide bleached Norway spruce mechanical pulp stored in different waters for 5 hours with a $5 \%$ or $15 \%$ pulp consistency at $50^{\circ} \mathrm{C}$ or $65^{\circ} \mathrm{C}$. The bars represent results for waters as received and the dots represent results for the corresponding sample after centrifugation. The error bars show the standard deviation of the optical measurements. a) The brightness of the pulp in process waters as compared to in distilled water at the time 0 hour. b) The light absorption coefficient $(k)$ at $460 \mathrm{~nm}$ of the pulp in process waters as compared to in distilled water at the time 0 hour. The variation of light scattering coefficient $(s)$ included in the figure at $460 \mathrm{~nm}$ for the pulp stored at $5 \%$ pulp consistency. c) The change in ISO brightness upon storage. d) The change in light absorption coefficient ( $k$ ) at $460 \mathrm{~nm}$ upon storage.

In general, there were small differences between waters "as received" or after centrifugation; though in most cases the increase in $k_{460}$ was smaller when pulp was stored in centrifuged waters. The WW PM stored at 5\% pulp consistency at $65{ }^{\circ} \mathrm{C}$ was the water where this difference was largest due to centrifugation. The WW PM was the process water that gave the largest increase in $k_{460}$. The WW PM had the highest brightness value of all waters both before and after storage but this was also the water that gave the highest increase in $k_{460}$. The brightness values after storage were quite similar for distilled water and CF PM even though the decrease in brightness was larger for CF PM.

Storage trials for longer periods of time were performed for all process waters except CF TMP (Fig 2a and b). The discolouration was also more pronounced after longer storage times when pulp was stored in any of the process waters compared to the case with distilled water, which gave the highest brightness and the lowest $k_{460}$ at all times studied (solid line in Fig 2).

All process waters gave quite similar results when used with the well-washed pulp, and at any given time the largest difference in brightness value was less than about 1.5 units. WW PM was the process water that gave the highest increase in $k_{460}$ after 5 hours of storage (Fig ld), this could also be seen in Fig 2b, but after longer times the other curves reached a similar level in $k_{460}$ as the washed pulp stored in the other process waters (grey shaded area in Fig 2b).

As a means of comparison, an unwashed pulp was also stored in distilled water and in WW PM. The brightness values were on the same level as those of the washed pulp (Fig 2a). The $k_{460}$-values, as a measure of the formation of colour, showed differences between washed and unwashed pulp. After short storage times, i.e. 5 hours, the increase in $k_{460}$ for the unwashed pulp in distilled water was similar to the increase for the washed pulp in distilled water. Though after longer storage times, the darkening of the unwashed pulp in distilled water became similar to that of the washed pulp stored in the process waters (open circles, broken line). When the unwashed pulp was stored in WW PM, the increase in $k_{460}$ was the highest at all times studied (broken line), showing the most extensive colour formation. This darkening did not show up as a decrease in brightness due to an increase in $s_{460}$ from 86.0 to $94.4 \mathrm{~m}^{2} \mathrm{~kg}^{-1}$. The reasons for the increase in $s_{460}$ are not known, but it is unlikely to contribute to the $s$-value of the finished paper. The coloured groups formed will eventually influence the brightness and whiteness of the finished paper made from 

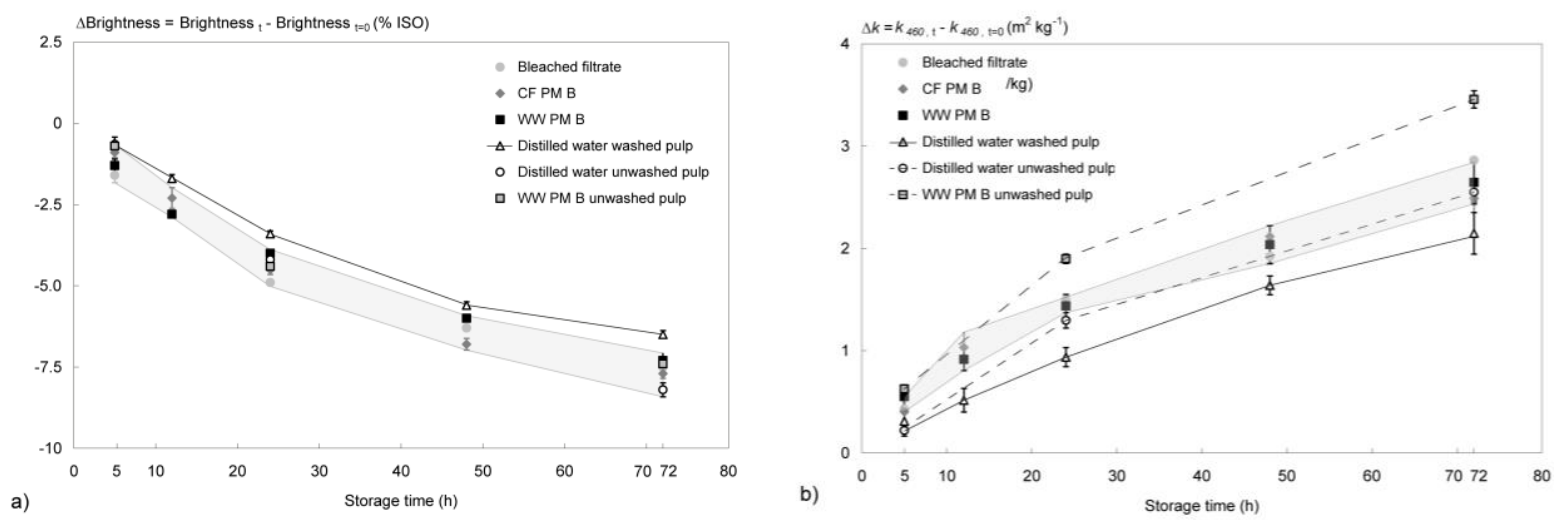

Fig 2 a-b - Change in ISO brightness and k460 during storage of unwashed or well-washed hydrogen-peroxide bleached Norway spruce mechanical pulp stored in different waters for $5-72 \mathrm{~h}$ at $5 \%$ pulp consistency and at $65^{\circ} \mathrm{C}$. The error bars show the standard deviation of the optical measurements. a) The change in ISO brightness upon storage. b) The change in light absorption coefficient $(k)$ at $460 \mathrm{~nm}$ upon storage. The lines and shaded areas are a guide to the eye.

this pulp. Furthermore, this difference indicates the importance of the cleanliness of pulp for avoiding the formation of colour during storage, both in distilled water and in process water.

It has been shown that the presence of clay, as in the WW PM samples, may be a major reason for the discolouration of pulp. In a study by Narvestad et al. (2013a) the "accessible iron" was proposed to cause the clay-induced discolouration. Different clays were stored together with DTPA, after which the iron content was measured in the water phase after centrifugation and filtration, and this iron content was defined as the accessible iron. The accessible iron constituted up to $\sim 30 \%$ of the total iron content in the clay. The WW PM B sample in this investigation was stored together with an excess of DTPA in order to estimate which amount of the possible $20 \mathrm{mg} \mathrm{L}^{-1}$ was accessible. The iron content of the filtered water phase accessible iron was found to be 1.9 $\mathrm{mg} \mathrm{L}^{-1}$, which is the same as before the DTPA treatment. This means that the DTPA could not solubilise the iron present in the sample. In the study by Narvestad et al. (2013a), fresh clay was used in the experiments, whereas in the present study the filler had been circulated in the white water for a period of time so the accessible iron may have been dissolved into the water during the circulation. Nevertheless, the WW PM gave high $k_{460^{-}}$ values after 5 hours of storage, both as received and after centrifugation.

Fig 3 shows the influence of $\mathrm{pH}$ during storage of pulp in distilled water or process waters WW PM or CF PM. The decrease in brightness was less when pulp was stored in distilled water compared to when it was stored in process waters (1-1.5 units compared to $2-3$ units. WW PM and CF PM showed similar results and are therefore represented by one solid curve. All waters were sensitive towards changes in $\mathrm{pH}$ and showed the lowest decrease in brightness at a $\mathrm{pH}$ of around 5.5-6.0, also shown as a minimum in $\Delta k_{460}$. These results are supported by the results presented by Narvestad et al. (2011) where hydrogen-peroxide bleached TMP was stored at $4 \%$ pulp consistency for 5 hours in distilled water or clear filtrate from the paper machine, CF PM, at various pHs. Though in their study the brightness loss was the least when $\mathrm{pH}$ was somewhat lower (5.0-5.5), the brightness loss at this $\mathrm{pH}$ interval was $\sim 1$ unit when pulp was stored in distilled water and $\sim 1.5$ units when pulp was stored in clear filtrate from the paper machine. The increase in the light absorption coefficient at $460 \mathrm{~nm}$ showed the same relation to $\mathrm{pH}$ as the decrease in brightness. The smallest increase in $k_{460}$ was seen at $\mathrm{pH}$ 5.5-6.0, and was lower when pulp was stored in distilled water compared to when it was stored in process waters. In a study by Gellerstedt et al. (1983), a minimum in relative colour formation, measured as $\Delta k / k_{0}=\left(\mathrm{k}_{\mathrm{a}}-\mathrm{k}_{0}\right) / \mathrm{k}_{0}$ at $457 \mathrm{~nm}$, where " 0 " is before treatment and "a" is after treatment, was seen at $\mathrm{pH} 5.5$.

Fig $4 a$ shows the light absorption coefficient $\left(k_{\lambda}\right.$ over the visible spectrum for pulp stored in the different waters. The values below $450 \mathrm{~nm}$ were considered unreliable as the light absorption was too strong (see e.g. Rundlöf et al. 1997; Karlsson et al. 2012). Therefore, these values were rejected.

The WW PM gave a broad shoulder in the absorption spectrum around 550-650 nm, which was present for both sampling occasions, $\mathrm{A}$ and $\mathrm{B}$. There were no shoulders in the absorption spectra for any of the other process waters or distilled water, these showed a smooth increase in $k$ with decreasing wavelength. The shoulder in the absorption spectra of WW PM could not be seen after centrifugation of the white water (broken line small steps), which shows that the shoulder in absorption spectra was related to particles which were removed by the centrifugation. In this case filler clay was probably involved (cf. Table 1). This shoulder in absorption spectra occurs in the same wavelength region where the added dyes have their absorption maxima (Fig 4a), which strongly indicates that this shoulder in absorption spectra was partly caused by added dyes adsorbed onto solid particles such as filler clay. 

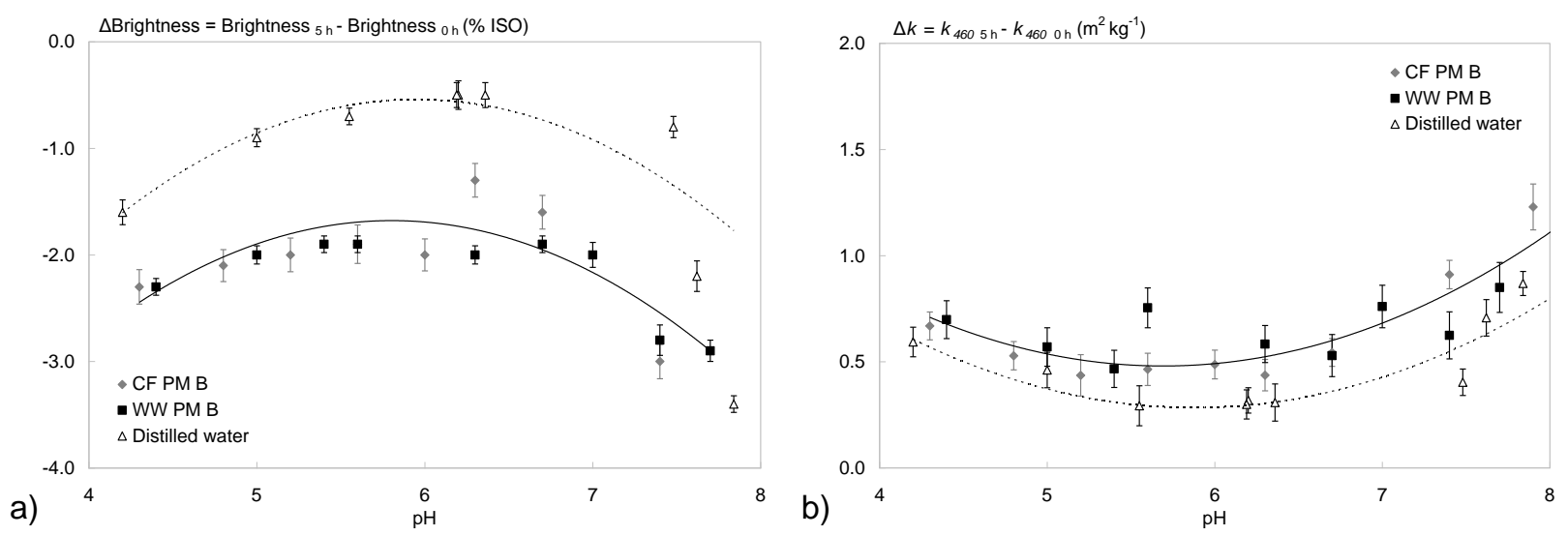

Fig $3 a-b$ - The influence of pH during storage of well-washed hydrogen-peroxide bleached Norway spruce mechanical pulp stored in different waters for 5 hours at $5 \%$ pulp consistency at $65^{\circ} \mathrm{C}$. The error bars show the standard deviation of the optical measurements. a) The change in ISO brightness upon storage. b) The change in light absorption coefficient ( $k$ ) at $460 \mathrm{~nm}$ upon storage.
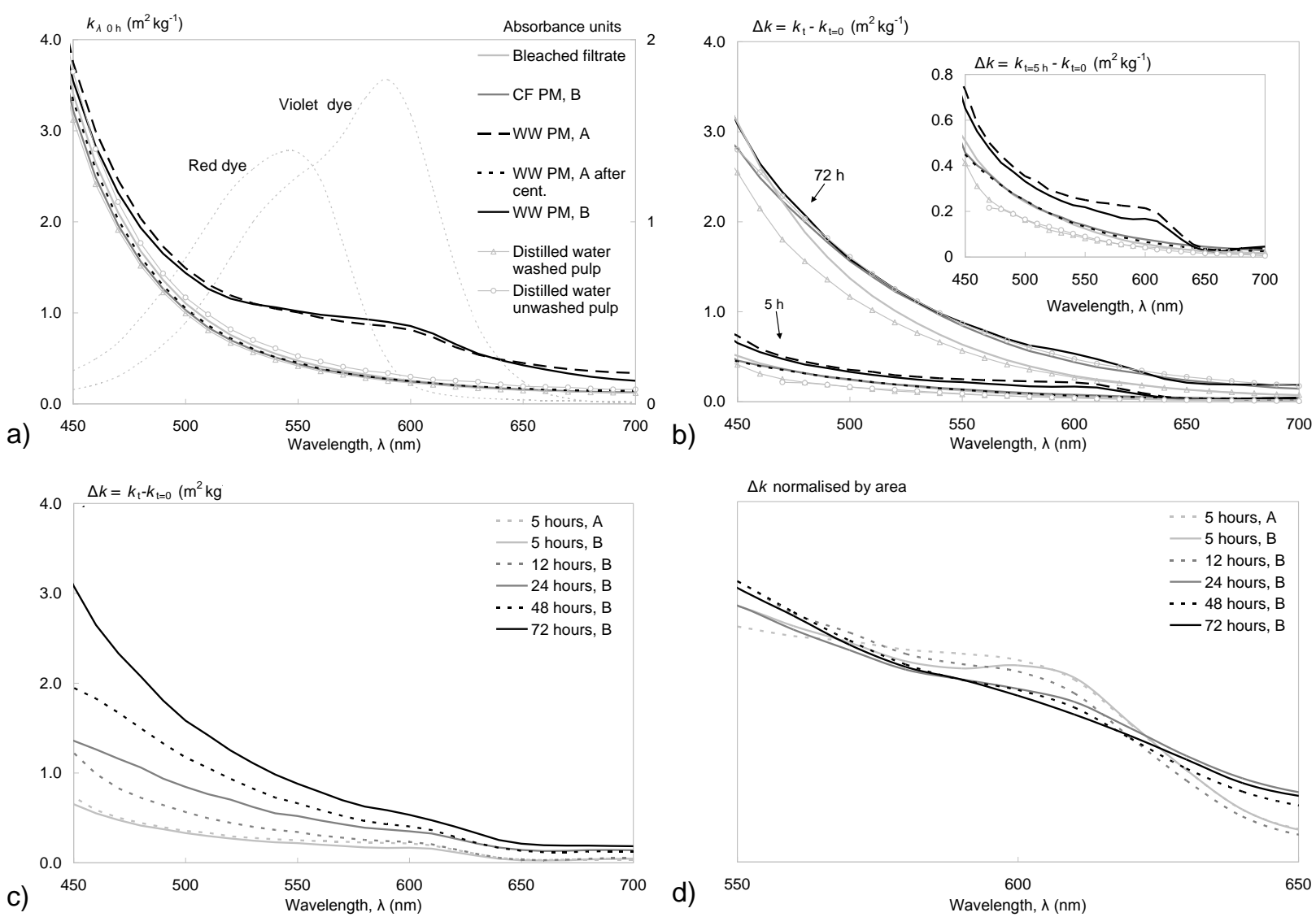

Fig 4 a-d - Spectral data for unwashed or well-washed hydrogen-peroxide bleached Norway spruce mechanical pulp upon dilution and/or storage in different waters. The WW PM was taken out on two different occasions marked A and B, data is also shown for WW PM after centrifugation. a) The light absorption coefficient over the visible spectra for pulp diluted to $5 \%$ consistency with different waters. On the secondary $y$-axis the absorbance spectra of the red and the violet dyes are shown. b) The difference spectra $\left(k_{\text {stored- }}\right.$ kunstored) for pulp stored in different waters at $5 \%$ pulp consistency at $65^{\circ} \mathrm{C}$ for 5 hours and 72 hours. The legends are the same as for 4a. The smaller picture within the figure shows storage for 5 hours with a different scale on the $y$-axis. c) The difference spectra ( $\left.k_{\text {stored- }} k_{\text {unstored }}\right)$ for pulp stored in WW PM (as received) at $5 \%$ pulp consistency at $65^{\circ} \mathrm{C}$ for $5,12,24,48$ and 72 hours. d) The curves in Figure 4c were normalised by the area, by dividing each value on a cure with the area under the same curve in the interval $550-$ $650 \mathrm{~nm}$. 


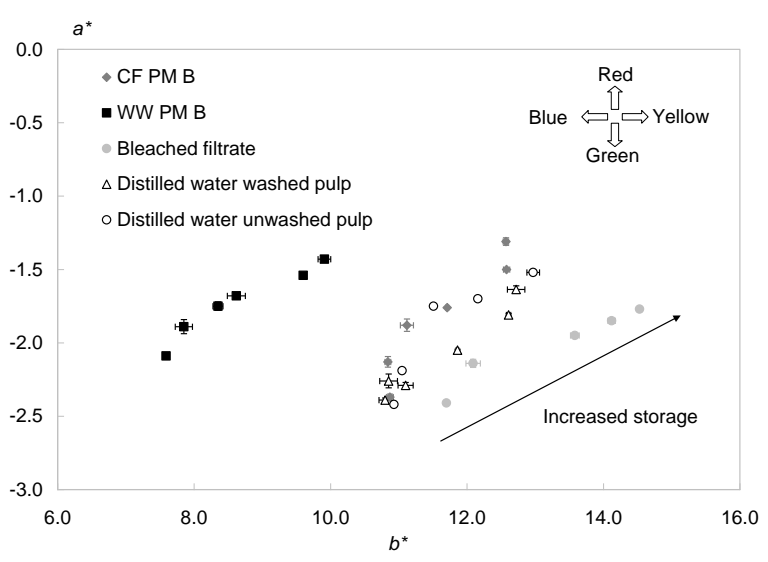

Fig 5 - The colour co-ordinates $a^{*}$ and $b^{*}$ for unwashed or wellwashed hydrogen-peroxide bleached Norway spruce mechanical pulp stored in different waters for 5-72 hours at 5\% pulp consistency at $65^{\circ} \mathrm{C}$. The error bars show the standard deviation of the optical measurements.

Fig $4 b$ shows the change in the light absorption coefficient during storage for all the waters shown in Fig $4 a$ at two different storage times -5 and $72 \mathrm{~h}$. Within the figure, the increase in $k$ after 5 hours of storage is shown as an inset with a magnified scale on the y-axis. The shoulder in absorption spectra at $550-650 \mathrm{~nm}$ was also present in the difference spectra $\left(k_{\text {stored }}-k_{\text {unstored }}\right)$ of WW PM, which shows that additional colour was formed at these wavelengths during storage. From mill experience there is nothing supporting the fact that the dyes themselves should darken during storage.

For all waters there was a general increase in $k$ with storage time, and the process waters showed a higher increase in $k$ than the distilled water. In Fig $4 c$, the difference spectra of WW PM for all storage times studied are shown. As can be seen in the figure, the shoulder in absorption spectra at $550-650 \mathrm{~nm}$ was present at all storage times. The light absorption coefficient increased with storage time over the whole wavelength region studied. For short storage times the increase in $k$ was most distinct at short wavelengths. Though, after storage over longer periods of time, the increase in $k$ became noticeable over the whole spectrum, also at longer wavelengths.

To evaluate the relative importance of the $k$-values in the wavelength region of the shoulder at every storage time, each curve was normalised by area; each value on a curve was divided by the area under this curve in the wavelength interval 550-650 nm (Fig 4d). For short storage times, $k$-values around $600 \mathrm{~nm}$ represent a larger part of that curve, whereas for longer storage times, $k$ values around $600 \mathrm{~nm}$ are not more important compared to $k$-values at other wavelengths. This means that for short times the darkening, measured as an increase in $k$, was especially pronounced around $\sim 600 \mathrm{~nm}$, whereas for long storage times there was a more general darkening in the interval $550-650 \mathrm{~nm}$.

It can be concluded that this shoulder in absorption spectra affects the reflectance of the pulp, as there was an obvious visible difference. Added dyes are partly the cause of this shoulder, as seen in Fig $4 a$, but probably not the only cause because the shoulder in absorption spectra becomes stronger during storage (Fig $4 b-d$ ). Darkening of this type of dyes (i.e. cationic basic dyes) with time has not been reported to our knowledge, rather the opposite; Liu et al. (2007) reported that the maximum absorbance of a cationic basic dye decreased with increasing temperature in the range $20-50^{\circ} \mathrm{C}$. Fig $4 b-d$ indicate that some other chromophores absorbing light in the same region were formed during storage. Any detailed characterisation of chromophores is beyond the scope of this work. However, the shoulder in absorption spectra at $550-650 \mathrm{~nm}$ coincides with some absorption maxima of complexes between ferric $\left(\mathrm{Fe}^{3+}\right)$ ions and lignin or extractive model compounds reported in the literature: Polcin and Rapson (1972) reported an absorption maximum of $550 \mathrm{~nm}$ for a complex between $\mathrm{Fe}^{3+}$ and D-catechin; Friman et al. (2004) reported an absorption maximum of $565 \mathrm{~nm}$ for a complex between $\mathrm{Fe}^{3+}$ and tannin; Gosh and $\mathrm{Ni}$ (1998) reported an absorption maximum of $\sim 590 \mathrm{~nm}$ for a complex between $\mathrm{Fe}^{3+}$ and catechol; Gore and Newman (1964) reported absorption maxima of $\sim 500-600 \mathrm{~nm}$ for complexes between $\mathrm{Fe}^{3+}$ and a range of different phenols. Moldenius (1983) also saw an absorption maximum at $585 \mathrm{~nm}$ when ferric sulfate was added to a hydrogen-peroxide bleached groundwood pulp, which was probably due to the ferricphenol complex with maxima at $590 \mathrm{~nm}$. The absorption bands of all the complexes named above are broad, in most cases over the whole visible spectrum, and broad absorption maxima are seen. The sholder present in the spectrum for WW PM will be further studied in a forthcoming paper.

Fig 5 shows the colour co-ordinates $\mathrm{CIE} a^{*}$ and $b^{*}$. All experiments gave a change in colour towards red and yellow as storage time increased, initially more towards red and then more towards yellow. This corresponds with previous experiments (Enberg et al. 2013). This way of representing changes in colour also shows that the discolouration begins at shorter wavelengths and then gradually becomes noticeable at longer wavelengths (cf. Fig $4 b-d$ ). It is obvious that the starting point was quite different when white water from the paper machine, WW PM, was used. This was most probably due to the added dyes, as mentioned above. The shift towards red was more pronounced for CF PM compared to the other waters. The $L^{*}$ values decreased with storage time in a similar way for all process waters, 2.0-2.7 units after $72 \mathrm{~h}$, and are not included here.

\section{Conclusions}

For all process waters, the discolouration was more pronounced when the pulp was stored in process water compared to in distilled water. At $50^{\circ} \mathrm{C}$ the discolouration was small or negligible, but when increasing the temperature to $65^{\circ} \mathrm{C}$ the discolouration increased as expected. For all waters, the increase in $k_{460}$ was less when the pulp was stored at a higher consistency, $15 \%$ compared to $5 \%$. In general there were small differences between waters "as received" and after centrifugation, although in most cases the increase in $k_{460}$ was smaller when pulp was stored in centrifuged waters. The white 
water from the paper machine was the process water that gave the highest increase in $k_{460}$ after 5 hours of storage, but after longer storage times the increase in $k_{460}$ was quite similar for all process waters studied. The waters were sensitive towards changes in $\mathrm{pH}$ and showed the lowest decrease in brightness and a corresponding minimum in $\Delta k_{460}$ at a $\mathrm{pH}$ around 5.5-6.0. The white water and clear filtrate from the paper machine showed similar results with a brightness decrease of 2-3 units, whereas storage in distilled water decreased the brightness less, by $1-1.5$ units. The white water from the paper machine gave a broad shoulder in the light absorption spectrum around $550-650 \mathrm{~nm}$, and the shoulder in absorption spectra was also present in the difference spectra $\left(k_{\text {stored }}-k_{\text {unstored }}\right)$, which indicates that additional colour was formed at these wavelengths during storage. The shoulder in the absorption spectra for the white water from the paper machine could not be seen after centrifugation, which shows that the shoulder in absorption spectra was related to particles which were removable by centrifugation. The absorption maxima of the added dyes occur in the same wavelength region as the shoulder in absorption spectra and are partly, but probably not only, the cause of it as the shoulder becomes stronger during storage. The shoulder in absorption spectra at 550-650 $\mathrm{nm}$ coincides with some absorption maxima of complexes between ferric ions and lignin or extractive model compounds reported in the literature. The additional darkening may be caused by the formation of some of these chromohphores. There were no shoulders in the absorption spectra of any of the other process waters or distilled water, these showed a smooth increase in $k$ with decreasing wavelength. CIE $L^{*}, a^{*}, b^{*}$ data showed that the storage changed the colour of the pulp towards red and yellow, initially more towards red and then more towards yellow.

The washing of pulp before storage seems to be an influencing factor, storage of unwashed pulp in similar experiments gave higher $k_{460}$-values both in distilled water and in white water from the paper machine. The difference between unwashed and washed pulp is at least as large as the difference between using distilled water or process water in these initial experiments.

\section{Acknowledgements}

Financial support from the Research Council of Norway and the Knowledge Foundation of Sweden is gratefully acknowledged. We would like to thank Norske Skog for supporting the project and for allowing the publication of some of their data.

\section{Literature}

Beyer, M., Bäurich, C. and Fischer, K. (1995): Mechanismen der licht- und wärmeinduzierten vergilbung von faserstoffen, Das Papier 49(10A), 8.

Chong, J.M., Nanayakkara, N.P.D. and Whiting, P. (1991): Model compound studies of thermal reversion chemistry, J. Pulp Paper Sci. 17(1), 18.

Ekman, R., Eckerman, C. and Holmbom, B. (1990): Studies on the behaviour of extractives in mechanical pulp suspensions, Nord. Pulp Paper Res. J. 5(2), 96.
Enberg, S., Rundlöf, M., Paulsson, M., Johnsen, I.A. and Axelsson, P. (2013): The influence of process conditions during pulp storage on the optical properties of Norway spruce mechanical pulps, Nord. Pulp Paper Res. J. 28(2), 203.

Ferritius, R. and Lundström, F. (2011): The effect of hydrogen peroxide containing filtrates and storage on unbleached and bleached pulp brightness, 28th Int. Mech. Pulp. Conf., Xian, China, June 26-29, pp. 255-258.

Forsskåhl, I. (2000): Brightness reversion, In: Stenius, P. (ed.), Forest Products Chemistry, Fapet Oy, Helsinki, pp. 278-332.

Forsskåhl, I., Tylli, H. and Olkkonen, C. (2000): Participation of carbohydrate-derived chromophores in the yellowing of highyield pulps, J. Pulp Paper Sci. 26(7), 245

Friman, L., Höglund, H. and Högberg, H.-E. (2004): Tanniniron impregnated thermomechanical pulp - part I - Effects of extractions and heat on brightness, Nord. Pulp Paper Res. J. 19(2), 229

Gellerstedt, G. and Pettersson, B. (1980): Autoxidation of lignin, Svensk Papperstidning 83(11), 314.

Gellerstedt, G., Pettersson, I. and Sundin, S. (1983): Lightinduced and heat-induced yellowing of mechanical pulps, Svensk Papperstidning 86(15), 157.

Ghosh, A. and Ni, Y. (1998): Metal ion complexes and their relationship to pulp brightness, J. Pulp Paper Sci. 24(1), 26.

Gore, P.H. and Newman, P.J. (1964): Quantitative aspects of the colour reaction between iron (III) and phenols, Anal. Chim. Acta 31(2), 111

Gratzl, J.S. (1985): Lichtinduzierte Vergilbung von Zellstoffen Ursachen und Verhütung, Das Papier 39(10A), 14.

Grossmann, K. and Ott, G.A. (1994): Licht- und hitzevergilbung unterschiedlicher papierfasestoffe - ein vergleich, Das Papier 48(10), 623.

Gupta, V.N. (1970): Effect of metal ions on brightness, bleachability and colour reversion of groundwood, Pulp Paper Mag. Can. 71(18), 69.

Harris, G. and Karnis A. (1986): Storage of latent mechanical pulps, J. Pulp Paper. Sci. 12(4), 100.

Hill, J., Sabourin, M., Johansson, L., Mörseburg, K., Axelsson, P., Aichinger, J., Braeuer, P. and Gorski, D. (2010): Combining selective bleaching chemistries and ATMP technology for low energy mechanical pulping at higher brightness, $7^{\text {th }}$ Int. Sem. Fund. Mech. Pulp Res., Nanjing, China, June 20-26, pp. 170-182.

Holmbom, B., Ekman, R. and Eckerman, C. (1992): Degradation products formed during light and heat treatments of spruce groundwood, J. Pulp Paper Sci. 18(4), 146.

Hon, D.N.S. and Glasser, W. (1979): On possible chromophoric structures in wood and pulps - A survey of the present state of knowledge, Polym. Plast. Technol. Eng. 12(2), 159.

Johnsen, I.A., Narvestad, H., Axelsson, P., Enberg, S., Aasarød, K. and Kure, K.-A. (2010): Metal induced brightness loss of peroxide bleached TMP, $7^{\text {th }}$ Int. Sem. Fund. Mech. Pulp Res., Nanjing, China, June 20-26, pp. 211-218.

Kallioranta, S. and Ostle, G. (2013): The next chapter, Paper $360^{\circ} 8(1), 8$. 
Karlsson, A., Enberg, S., Rundlöf, M., Paulsson, M. and Edström, P. (2012): Determining optical properties of mechanical pulps, Nord. Pulp Paper Res. J. 27(3), 531.

Kuizhong, S., Guigan, F. and Ping, L. (2010): Bleaching of CTMP pulps from nine wood species, $7^{\text {th }}$ Int. Sem. Fund. Mech. Pulp Res., Nanjing, China, June 20-26, pp. 196-201.

Liu, H., Yang, S. and Ni, Y. (2007): Using dyes for improving the optical properties of high yield pulps, Pulp Paper Can. 108(10), 25.

Lunan, W.E., Sferrazza, M.J., Fransén, R.G. and May, W.D. (1986): Curl-setting during storage of thermomechanical pulp at high consistency, J. Pulp Paper Sci. 12(4), 108.

Luo, C., Putz, L. and Göttsching, L. (1988): Untersuchungen zur licht- und hitzeinduzierten vergilbung von gebleichten ligninhaltigen primär- und sekundärfaserstoffen, Das Papier 42(10A), 55.

Mao, C. and Ni, Y. (2008): Effect of metal ion contamination in the process water on the brightness of peroxide- and hydrosulphite- bleached mechanical pulps, J. Pulp Paper Sci. 34(2), 129.

Meshitsuka, G. and Nakano, J. (1973): Effect of metal ion on color of lignosulfonate and thiolignin, Tappi 56(7), 105.

Moldenius, S. (1983): Light absorption coefficient spectra of hydrogen peroxide bleached mechanical pulps, Paperi Puu 65(11), 747.

Narvestad, H., Axelsson, P. and Kure, K.-A. (2011): Full scale experiences with magnesium hydroxide based peroxide bleaching and TMP brightness loss at Norske Skog Saugbrugs, $28^{\text {th }}$ Int. Mech. Pulp Conf., Xian, China, June 26-29, pp. 287290.

Narvestad, H., Gregersen, Ø.W. and Kure, K.-A. (2013a): Filler clay induced discolouration of bleached mechanical pulp, Nord. Pulp Paper Res. J. 28(1), 68.

Narvestad, H., Gregersen, Ø.W. and Kure, K.-A. (2013b): Reaction kinetics and mechanisms of filler clay-induced discolouration of bleached mechanical pulp, Nord. Pulp Paper Res. J. 28(3), 331.

Narvestad, H., Gregersen, Ø.W. and Kure, K.-A. (2013c): Effect of sodium dithionite post-bleaching on the clay-induced discolouration of a hydrogen peroxide bleached mechanical pulp, Nord. Pulp Paper Res. J. 28(3), 342.

Ni, Y., Li, Z. and Van Heiningen, A.R.P. (1997): Minimization of brightness loss due to metal ions in the process water for bleached mechanical pulps, Pulp Paper Can. 98(10), 72.

Ni, Y., Ng, A. and Mosher, M. (1999): A model compound study - The formation of colored metallic extractive complexes and their effect on the brightness of TMP pulp, J. Wood Chem. Technol. 19(3), 213.

Paulsson, M. and Parkås, J. (2012): Review: Light induced yellowing of lignocellulosic pulps - Mechanisms and preventive methods, BioRes. 7(4), 5995.

Peart, C. and Ni, Y. (2001): UV-VIS spectra of lignin model compounds in the presence of metal ions and chelants, $\mathrm{J}$. Wood Chem. Technol. 21(2), 113.

Polcin, J., Wayman, M., Anderson, C.B. and Rapson, W.H. (1969): Sapwood and heartwood groundwood of western hemlock and jack pine - part I - Influence of extractives on optical properties, Pulp Paper Mag. Can. 70(21), 91.

Polcin, J. and Rapson, W.H. (1972): Sapwood and heartwood groundwood of western hemlock and jack pine - part III Influence of solvent extractions on the bleaching of pulps, Pulp Paper Mag. Can. 73(1), 86.

Rundlöf, M. and Bristow, J.A. (1997): A note concerning the interaction between light scattering and light absorption in the application of the Kubelka-Munk equations, J. Pulp Paper Sci. 23(5), 220.

Rundlöf, M., Htun, M., Höglund, H. and Wågberg, L. (2000a): The importance of the experimental method when evaluating the quality of fines of mechanical pulp, J. Pulp Paper Sci. 26(9), 301.

Rundlöf, M., Htun, M., Höglund, H. and Wågberg, L. (2000b): Mechanical pulp fines of poor quality - Characteristics and influence of white water, J. Pulp Paper Sci. 26(9), 308.

Thornton, J., Eckerman, C. and Ekman, R. (1991): Effects of peroxide bleaching of spruce TMP on dissolved and colloidal organic substances, 6th Int. Symp. Wood Pulp. Chem., Melbourne, Australia, April 29-May 3, Vol. 1, pp. 571-577.

Varhimo, P., Konn, J., Lilland, M. and Paltakari, J. (2012): Brightness reduction of mechanical pulp in the wet end of a paper machine - Method development and validation, Nord. Pulp Paper Res. J. 27(3), 542.

Yoon, B.H., Wang, L.J. and Kim, G.S. (1999): Formation of lignin-metal complexes by photo-irradiation and their effect on colour reversion of TMP, J. Pulp Paper Sci. 25(8), 289.

Zhang, L. and Gellerstedt, G. (1994): Quinoid lignin chromophores and their contribution to photoyellowing, $3^{\text {rd }}$ European workshop on lignocellulosics and pulp, Stockholm, Sweden, August 28-31, pp. 293-295.

Örså, F. and Holmbom, B. (1994): A convenient method for the determination of wood extractives in papermaking process waters and effluents, J. Pulp Paper Sci. 20(12), 361.

Manuscript received February 10, 2014 Accepted April 16, 2014 